\title{
PERILAKU IBU NIFAS DALAM MENGKONSUMSI KAPSUL VITAMIN A DI KECAMATAN KOTA PINANG KABUPATEN LABUHANBATU SELATAN
}

\author{
Putra Apriadi Siregar ${ }^{1}$ \\ 1 Universitas Islam Negeri Sumatera Utara \\ Email: siregar.putra56@gmail.com \\ DOI : $\underline{10.24252 / \text { kesehatan.v12i1.7934 }}$
}

\begin{abstract}
Abstrak
Tindakan ibu nifas dalam mengkonsumsi kapsul vitamin A sangatlah penting. Periode masa nifas pada seorang ibu membuat ibu nifas harus memenuhi kebutuhan vitamin A untuk ibu nifas dan anaknya. Kekurangan vitamin A pada ibu nifas akan dapat mengakibatkan penurunan daya tahan tubuh baik pada ibu nifas maupun kepada bayi. Kabupaten Labuhanbatu Selatan memiliki cakupan vitamin A sangat rendah jika dibandingkan dengan kabupaten lainnya di Provinsi Sumatera Utara. Penelitian menggunakan jenis deskriptif dengan design cross sectional. Populasi penelitian ini sebanyak 355 orang ibu nifas di Kecamatan Kota Pinang dan sampel dalam penelitian ini sebanyak 57 orang ibu nifas. Instrumen dalam penelitian ini menggunakan kuesioner berstruktur yang sudah dipersiapkan. Penelitian ini disajikan data distribusi dalam bentuk tabel frekuensi. Hasil penelitian ini menunjukkan bahwa sebagian besar responden memiliki kategori tindakan sedang yaitu sebanyak 52 orang (91,2\%), sedangkan selebihnya berada pada kategori tindakan buruk yaitu sebanyak 5 orang $(8,8 \%)$. Seluruh responden atau sebanyak 57 orang $(100 \%)$ responden memiliki sikap dengan kategori sedang. Hasil penelitian ini menunjukkan bahwa sebagian besar responden memiliki kategori pengetahuan sedang yaitu sebanyak 38 orang $(66,7 \%)$ dan kategori pengetahuan baik yaitu sebanyak 19 orang (33,3\%). Diharapkan agar petugas kesehatan Puskesmas di Kecamatan Kota Pinang dan pemuka masyarakat turut berpartisipasi dalam memberikan informasi mengenai konsumsi kapsul Vitamin A kepada ibu nifas. Diharapkan kepada ibu nifas untuk mengkonsumsi kapsul Vitamin A segera setelah diberikan oleh petugas kesehatan (bidan) setelah melakukan kunjungan nifas.
\end{abstract}

\section{Kata Kunci: Perilaku; Ibu Nifas; Konsumsi; Kapsul Vitamin A}

\begin{abstract}
The act of childbirth in consuming vitamin A capsules is very important, the puerperium period becomes a very important for the mother and babies. The period of childbirth in a mother makes the postpartum mother must meet the needs of vitamin A for postpartum mothers and their children. Vitamin A deficiency in postpartum mothers will lead to a decrease in immunity both in postpartum mothers and infants. Labuhanbatu Selatan Regency has very low coverage of vitamin A when compared to other districts in North Sumatra Province. The study used descriptive type with cross sectional design. The population of this study were 355 postpartum mothers in Kota Pinang District and the sample in this study were 57 postpartum mothers. The instrument in this study uses a structured questionnaire that has been prepared. This research presents distribution data in the form of frequency tables.
\end{abstract}


The results of this study indicate that the majority of respondents had a moderate action category which was as many as 52 people (91.2\%), while the rest were in the category of bad actions as many as 5 people $(8.8 \%)$. All respondents or as many as 57 people $(100 \%)$ respondents had an attitude with a moderate category. The results of this study indicate that the majority of respondents have a medium knowledge category that is as many as 38 people (66.7\%) and good knowledge categories as many as 19 people (33.3\%). It is expected that Puskesmas health workers in Kota Pinang Sub-district and community leaders will participate in providing information about taking Vitamin A capsules to postpartum mothers. It is expected that postpartum mothers will take Vitamin A capsules immediately after being given by health workers (midwives) after a postpartum visit.

Keywords: Behavior; Postpartum Mothers; Consumption; Vitamin A Capsules

\section{PENDAHULUAN}

Vitamin A memegang peranan penting dalam fungsi tubuh, termasuk fungsi penglihatan, imunitas, serta perkembangan dan pertumbuhan embrio. Kapsul vitamin A memberikan banyak manfaat bagi ibu nifas, yaitu meningkatkan kandungan vitamin A dalam Air Susu Ibu (ASI); bayi lebih kebal dan jarang kena penyakit infeksi; kesehatan ibu lebih cepat pulih setelah melahirkan; ibu nifas harus minum 2 kapsul vitamin A karena bayi lahir dengan cadangan vitamin A yang rendah, kebutuhan bayi akan vitamin A tinggi untuk pertumbuhan dan peningkatan daya tahan tubuh; pemberian 1 kapsul vitamin A 200.000 IU warna merah pada ibu nifas hanya cukup untuk meningkatkan kandungan vitamin A dalam ASI selama 60 hari, sedangkan dengan pemberian 2 kapsul dapat menambah kandungan vitamin A sampai bayi 6 bulan (Kementerian Kesehatan RI, 139-140).

Ibu nifas sepatutnya mendapatkan pelayanan kesehatan seperti pemberian vitamin A. Menurut Kementerian Kesehatan RI bahwa pemberian kapsul merah vitamin A dosis tinggi (200.000 IU) kepada ibu nifas sebanyak dua buah, yaitu 1 (satu) kapsul diminum segera setelah persalinan dan 1 (satu) kapsul diminum 24 jam sesudah pemberian kapsul pertama ( Kementerian Kesehatan RI, 438).Ibu nifas secara fisiologis membutuhkan vitamin A yang lebih banyak dibandingkan dengan wanita dewasa biasa. Angka kecukupan gizi vitamin A di Indonesia untuk seorang wanita dewasa adalah 500 retinol equivalent (RE) per hari, +300RE per hari pada ibu hamil , +350RE pada saat si ibu menyusui ditambah dengan kebutuhan vitamin A pada bayi 0-6 bulan sebesar 375RE (Almatsier, 250 ).

Hasil penelitian Salam (212-212) memperlihatkan bahwa pemberian 2 kapsul vitamin A dosis tinggi yang diberikan kepada responden terbukti lebih baik dalam mengurangi kejadian morbiditas pada ibu dan bayi dibandingkan dengan pemberian 1 kapsul vitamin A. Hasil penelitian Bando (6-7) menunjukkan bahwa responden yang diberikan suplementasi Vitamin A tidak menderita sakit sebulan terakhir dan sebagian besar responden yang tidak diberikan suplementasi Vitamin A menderita sakit sebulan terakhir. Hasil penelitian Wahyuni (140) juga memperlihatkan bahwa anak yang memiliki asupan vitamin A yang cukup didalam tubuhnya cenderung tidak menderita diare dibandingkan anak yang memiliki asupan vitamin A yang kurang di dalam tubuhnya. 
Hasil penelitian Oliveira (60-70) menunjukkan bahwa konsumsi retinol dosis tinggi 200.000 IU selama satu bulan post partum sangat bermanfaat di daerah yang memiliki devisiensi Vitamin A. Hasil penelitian Geogia (22-24) menunjukkan bahwa pemberian kapsul vitamin A kepada ibu nifas terbukti dapat mencegah morbiditas dan kematian bayi. Penelitian yang dilakukan Yanti (6-7) juga mengungkapkan bahwa konsumsi kapsul vitamin A dengan lengkap akan membuat anak memiliki risiko yang rendah terkena penyakit campak dibandingkan konsumsi vitamin A tidak lengkap.

Kapsul vitamin A dosis tinggi terbukti efektif untuk mengatasi masalah kekurangan vitamin A (KVA) pada ibu nifas dan bayi apabila cakupannya tinggi. Peraturan Menteri Kesehatan Nomor 21 Tahun 2015, dinyatakan bahwa untuk mengurangi risiko kesakitan dan kematian pada balita dengan kekurangan Vitamin A, pemerintah menyelenggarakan kegiatan pemberian Vitamin A dalam bentuk kapsul Vitamin A biru 100.000 IU bagi bayi usia enam sampai dengan sebelas bulan, kapsul vitamin A merah 200.000 IU untuk anak balita usia dua belas sampai dengan lima puluh sembilan bulan, dan ibu nifas.

Cakupan pemberian vitamin A untuk ibu nifas di Indonesia masih tergolong rendah, walaupun demikian ada kecenderungan cakupannya makin meningkat selama tiga tahun terakhir. Dengan demikian masih diperlukan upaya-upaya untuk meningkatkan cakupan tersebut, antara lain melalui peningkatan integrasi pelayanan kesehatan ibu nifas, sweeping pada daerah yang cakupannya masih rendah, dan kampanye pemberian kapsul vitamin A (Kementerian Kesehatan RI, 204)

Hasil penelitian Prastiwi (8-9) memperlihatkan bahwa bidan memiliki peranan yang cukup besar terhadap kepatuhan ibu nifas dalam mengkonsumsi kapsul vitamin A. Hasil penelitian Sanjaya (3-7) juga mengungkapkan bahwa faktor yang memengaruhi cakupan vitamin A pada ibu nifas adalah mendapatkan pelayanan neonatus (AOR = 2,334 95\% CI 2,1562,530), pemberian tablet tambah darah (AOR $=2,076,95 \%$ CI 1,874-2,298), ANC (AOR = 1,355, 95\% CI 1,217-1,510), imunisasi TT (AOR = 1,245, 95\% CI 1,156-1,341), pendidikan ibu tamat SD $(\mathrm{AOR}=1,18895 \%$ CI 1,051-1,342). Hasil penelitian Febriani (8-9) juga menunjukkan bahwa pengetahuan berhubungan dengan tindakan dalam mengkonsumsi kapsul vitamin $\mathrm{A}$.

Sumatera Utara merupakan salah satu daerah yang memiliki cakupan pemberian vitamin A yang cukup rendah apabila dibandingkan dengan cakupan pemberian vitamin A untuk ibu nifas di provinsi lainnya di Indonesia. Berdasarkan data Kementerian Kesehatan tahun 2013 menunjukkan persentase cakupan pemberian vitamin A ibu nifas di Provinsi Sumatera Utara hanya sebesar 37,8\% yang menjadikan Sumatera Utara menjadi 4 besar provinsi yang memiliki cakupan pemberian kapsul vitamin A terendah bersama dengan Provinsi Aceh, Jambi dan Papua Barat ( Kementerian Kesehatan RI, 204). Hal ini akan menjadi permasalahan yang sangat serius bagi masa depan Provinsi Sumatera Utara ke depannya terkait permasalahan morbiditas ibu nifas dan bayinya.

Berdasarkan laporan bidang pelayanan kesehatan Dinas Kesehatan Kabupaten Labuhanbatu Selatan pada tahun 2014, bahwa cakupan program pemberian kapsul vitamin A pada ibu nifas sebesar 41,93\%, dimana hanya 2 dari 11 puskesmas yang memiliki jumlah cakupan pemberian vitamin A pada ibu nifas mendekati target $100 \%$, bahkan terdapat 5 puskesmas yang jumlah cakupan pemberian kapsul vitamin A pada ibu nifas kurang dari $50 \%$. 
Angka realisasi cakupan program pemberian kapsul vitamin A setiap puskesmas di Kabupaten Labuhanbatu Selatan selama tahun 2014 cukup memprihatinkan. Situasi tidak tercapainya cakupan program pemberian kapsul vitamin A pada ibu nifas terjadi di sejumlah puskesmas di Kabupaten Labuhanbatu Selatan. Sebahagian besar puskesmas menunjukkan cakupan program pemberian kapsul vitamin A pada ibu nifas tidak mencapai target dari pemerintah yaitu 100\% pemberian kapsul vitamin A kepada ibu nifas .

Kecamatan Kota Pinang memiliki jumlah ibu nifas sebanyak 1029 orang tetapi hanya 287 orang ibu nifas $(27,89 \%)$ yang mendapatkan kapsul vitamin. Pemberian kapsul vitamin A di Kecamatan Kota Pinang termasuk terendah di Kabupaten Labuhanbatu Selatan . Berdasarkan data dari Kecamatan Kota Pinang menunjukkan bahwa cakupan pemberian kapsul vitamin A di Kecamatan kota Pinang masih mengalami perbedaan yang tajam pada setiap enam bulannya sehingga menimbulkan pertanyaan bagi setiap orang yang mengamatinya. Cakupan program pemberian kapsul vitamin A pada ibu nifas di Kecamatan Kota Pinang ini masih sangat jauh dari harapan kita, dimana cakupan pemberian kapsul vitamin A di Kecamatan Kota Pinang masih jauh dari target pemerintah $100 \%$. Situasi tidak tercapainya cakupan program pemberian kapsul vitamin A pada ibu nifas terjadi di Kecamatan Kota Pinang di Kabupaten Labuhanbatu Selatan akan menjadi suatu permasalahan di bidang kesehatan dalam beberapa tahun ke depannya.

\section{METODOLOGI PENELITIAN}

Penelitian ini menggunakan pendekatan kuantitatif dengan design cross sectional. Penelitian dilakukan di Kecamatan Kota Pinang Kabupaten Labuhanbatu Selatan. Adapun alasan peneliti dalam memilih lokasi karena cakupan pemberian kapsul vitamin A yang rendah di Kecamatan Kota Pinang yang tidak memenuhi cakupan yang ditentukan oleh Kementerian Kesehatan RI yaitu sebesar 51,4 \% pada bulan Agustus 2013 sampai dengan Februari 2014 dan mengalami penurunan yang tajam menjadi 17,8\% pada bulan Februari 2014 sampai dengan Agustus 2015, padahal pemerintah memberikan target cakupan pemberian vitamin A 100\% pada ibu nifas.

Populasi dalam penelitian ini adalah seluruh ibu nifas yang berada di Kecamatan Kota Pinang Kabupaten Labuhanbatu Selatan tahun 2016 yaitu sebanyak 355 orang ibu nifas. Sampel dalam penelitian ini adalah sebagian dari jumlah ibu nifas yang berada Kecamatan Kota Pinang Kabupaten Labuhanbatu Selatan. Jumlah sampel yang akan diteliti dihitung dengan menggunakan rumus, sebagai berikut .

$$
\begin{aligned}
& n=\frac{Z^{2} \cdot P(1-P) \cdot N}{d^{2} \cdot(N-1)+Z^{2} \cdot P(1-P)} \\
& n=\frac{1,645^{2} \cdot 0,5(1-0,5) \cdot 355}{0,1^{2} \cdot(355)+1,645^{2} \cdot 0,5(1-0,5)} \\
& \mathrm{n}=56,8 \\
& \mathrm{n}=57
\end{aligned}
$$


Cara pengambilan sampel untuk penelitian ini adalah dengan teknik pengambilan sampel Non random Sampling yaitu dengan cara Purposive Sampling dimana pengambilan sampel berdasarkan kriteria yang dibuat oleh peneliti. Kriteria responden yang akan menjadi sampel :

1. Ibu nifas yang tercatat sebagai penduduk tetap di wilayah Kecamatan Kota Pinang.

2. Ibu nifas telah mendapatkan minimal kunjungan pertama neonatal (6-48 jam) pasca melahirkan.

3. Ibu nifas melahirkan dengan anak lahir selamat .

4. Bersedia dilakukan wawancara

5. Tinggal di lokasi penelitian minimal selama 3 bulan terakhir

Data primer diperoleh dengan hasil pengumpulan data terhadap responden melalui wawancara langsung dengan kuesioner penelitian yang sudah dipersiapkan untuk mengetahui pengetahuan, sikap dan tindakan ibu nifas dalam mengkonsumsi kapsul vitamin A di Kecamatan Kota Pinang Kabupaten Labuhanbatu Selatan. Data sekunder yang diperlukan dalam penelitian ini diperoleh dari Kecamatan Kota Pinang Kabupaten Labuhanbatu Selatan, instansi lain yang berkaitan dan hasil-hasil penelitian sebelumnya. Instrumen dalam penelitian ini menggunakan kuesioner. Teknik dan pengolahan data dilakukan dengan menggunakan komputer program komputer untuk menyajikan data dalam bentuk frekuensi dan persentase kemudian hasilnya disajikan dalam tabel

\section{HASIL DAN PEMBAHASAN}

Penelitian ini dilakukan di Kecamatan Kota Pinang Kabupaten Labuhanbatu Selatan dengan jumlah responden sebanyak 57 orang ibu nifas. Penelitian ini dilakukan dengan menggunakan wawancara melalui kuesioner berstruktur yang sudah dipersiapak sebelumnya.

Tabel 1. Distribusi Pengetahuan, Sikap dan Tindakan Ibu Nifas dalam mengkonsumsi Kapsul Vitamin A di Kecamatan Kota Pinang Kabupaten Labuhanbatu Selatan

\begin{tabular}{ccc}
\hline Kategori Pengetahuan & Jumlah & $\mathbf{\%}$ \\
\hline Baik & 19 & 33,3 \\
Sedang & 38 & 66,7 \\
Buruk & 0 & 0 \\
\hline Jumlah & 57 & 100,0 \\
\hline Kategori Sikap & Jumlah & $\mathbf{0}$ \\
\hline Baik & 0 & 0 \\
Sedang & 57 & 100,0 \\
Buruk & 0 & 0 \\
\hline Jumlah & 57 & 100,0 \\
\hline Kategori Tindakan Ibu Nifas & Jumlah & 0 \\
\hline Baik & 0 & 91,2 \\
\hline Sedang & 52 & 8,8 \\
\hline Buruk & 5 & 100,0
\end{tabular}


Berdasarkan Tabel 1 diketahui bahwa sebagian besar responden memiliki pengetahuan dalam kategori sedang yaitu sebanyak 38 orang $(66,7 \%)$, sedangkan selebihnya berada pada kategori tindakan baik yaitu sebanyak 19 orang (33,3\%). Seluruh responden atau sebanyak 57 orang $(100 \%)$ responden memiliki sikap dengan kategori sedang. Hasil penelitian ini menunjukkan bahwa sebagian besar responden memiliki tindakan konsumsi kapsul vitamin A dalam kategori sedang yaitu sebanyak 52 orang $(91,2 \%)$ dan tindakan konsumsi kapsul vitamin A kategori buruk yaitu sebanyak 5 orang $(8,8 \%)$.

\section{Pengetahuan Ibu Nifas Tentang Konsumsi kapsul Vitamin A}

Pengetahuan yang baik diperoleh dari proses pembelajaran yang baik, dengan demikian penyebab tingginya angka responden yang memiliki pengetahuan kurang baik salah satunya yaitu kurangnya informasi yang bisa diterima responden saat mendapatkan informasi kesehatan. Pengetahuan merupakan hasil dari tahu dan ini terjadi setelah orang melakukan penginderaan terhadap suatu objek tertentu seperti mengikuti pendidikan kesehatan. Pengetahuan merupakan domain yang sangat penting untuk terbentuknya tindakan seseorang. Sesuai dengan hasil penelitian ternyata perilaku yang didasari oleh pengetahuan akan lebih langgeng daripada perilaku yang tidak didasari oleh pengetahuan.

Hasil penelitian ini menunjukkan bahwa sebagian besar responden memiliki pengetahuan dalam kategori sedang yaitu sebanyak 38 orang $(66,7 \%)$, sedangkan selebihnya berada pada kategori tindakan baik yaitu sebanyak 19 orang (33,3\%). Hasil penelitian Kusumawati (31-33) menunjukkan bahwa ibu nifas banyak yang tidak mengetahui pemberian kapsul vitamin A terutama terkait ketepatan waktu dalam mengkonsumsi kapsul vitamin A. Hasil penelitian Putri (7-8) menunjukkan bahwa masih berimbang jumlah ibu nifas yang memiliki pengetahuan rendah (47\%) dan pengetahuan tinggi (53\%).

Penelitian yang dilakukan Kurniwati (135-136) menunjukkan bahwa banyaknya ibu nifas yang memiliki pengetahuan rendah tentang konsumsi kapsul vitamin A dapat terjadi disebabkan ibu nifas tidak mengetahui pelaksanaan pemberian kapsul vitamin A. Ibu nifas kurang memahami maksud pemberian kapsul vitamin A yang diberikan kepada mereka, kurangnya keaktifan ibu nifas dalam mengikuti berbagai kegiatan sosialisasi dan pelatihan tentang pelayanan nifas membuat ibu nifas tidak terpapar informasi tentang kapsul vitamin A. Hasil penelitian Bando (4-5) bahwa ibu yang sudah merasakan manfaat pemberian kapsul vitamin A akan cenderung memiliki pengetahuan yang baik tentang kapsul vitamin A bahkan sebahagian besar mengkonsumsi vitamin A dengan baik dan benar. Penelitian yang dilakukan Sandjaja (4-5) memperlihatkan bahwa ibu yang memiliki pendidikan SMA dan perguruan tinggi, ibu dengan paritas pertama dan kedua cenderung memiliki pengetahuan yang baik tentang vitamin A.

Pengetahuan yang didapatkan responden menjadi baik disebabkan sebahagian besar responden memiliki karakteristik berusia 20-30 tahun yang membuat reponden dapat mengikuti berbagai kegiatan penyuluhan dan pelayanan nifas yang diberikan oleh bidan yang membuat ibu dapat menerima informasi tentang vitamin A dan manfaat konsumsi vitamin A dengan baik. Umur responden yang tidak terlalu tua membuat responden masih memiliki kemampuan penerimaan atau mengingat yang diberikan ibu bidan dalam kategori baik. Pengetahuan responden dalam kategori sedang juga dapat terjadi disebabkan responden 
sebahagian besar sudah pernah melahirkan membuat responden sudah memiliki pengalaman dalam melakukan pelayanan nifas kepada tenaga kesehatan sehingga responden akan semakin mudah untuk memutuskan untuk menerima atau menolak informasi yang diberikan.

Ibu nifas dalam penelitian ini memiliki pengetahuan yang rendah terkait manfaat yang akan diterima ibu nifas jika mengkonsumsi kapsul vitamin A dan waktu yang sebaiknya dalam mengkonsumsi kapsul vitamin A. Setelah ibu nifas mendapatkan pelayanan nifas dari bidan maka ibu nifas akan diberi kapsul vitamin A seusai melahirkan, ibu nifas pada umumnya tidak pernah bertanya kepada bidan yang menolong persalinan mereka mengenai manfaat dan pentingnya kapsul vitamin A pada ibu nifas yang diberikan. Bidan di desa juga hanya memberikan kapsul tersebut dengan hanya menjelaskan aturan minum tanpa menjelaskan manfaat dan pentingnya kapsul vitamin A pada ibu nifas. Sehingga ibu nifas hanya sekedar menerima kapsul vitamin A tanpa mengetahui manfaat dan pentingnya kapsul vitamin A tersebut.

Pengetahuan seseorang erat kaitannya dengan perilaku yang akan diambilnya, karena dengan pengetahuan tersebut ia memiliki alasan dan landasan untuk menentukan suatu pilihan. Kurangnya pengetahuan tentang kapsul vitamin A akan mengakibatkan rendahnya tindakan si ibu dalam mengkonsumsi kapsul vitamin A . Kemungkinan seseorang akan berbuat sesuatu tergantung pada hasil perpaduan dari keinginan bahwa kegiatan yang dilakukan akan bisa mencapai tujuan yang diinginkan, pentingnya tujuan tersebut menurut yang bersangkutan dan sarana maupun usaha yang diperlukan itu. Salah satu strategi penting dalam upaya meningkatkan konsumsi vitamin A adalah dengan meningkatkan pengetahuan ibu tentang akibat dan manfaat yang akan didapatkan jika mengkonsumsi kapsul vitamin A sehingga akan menimbulkan kesadaran dari dalam diri yang nantinya dapat meningkatkan tindakan ibu nifas dalam mengkonsumsi kapsul vitamin A. Pengetahuan seseorang erat kaitannya dengan perilaku yang akan diambilnya, karena dengan pengetahuan tersebut ia memiliki alasan dan landasan untuk menentukan suatu pilihan. Kurangnya pengetahuan tentang kapsul vitamin A mengakibatkan ibu nifas tidak mengkonsumsi kapsul vitamin A.

\section{Sikap Ibu Nifas Tentang Konsumsi Kapsul Vitamin A}

Suatu sikap belum optimis terwujud dalam suatu tindakan. Untuk terwujudnya sikap menjadi suatu perbuatan nyata diperlukan faktor pendukung/suatu kondisi yang memungkinkan. Oleh karena itu, seharusnya ibu nifas melakukan tindakan yang baik dengan sudah mendapatkan kapsul vitamin pada kurun waktu yang ditentukan agar responden mendapatkan manfaat yang maksimal. Hal ini termasuk kedalam tingkatan tindakan respon terpimpin (guided response) yaitu dapat melakukan sesuatu sesuai dengan urutan yang benar dan sesuai dengan contoh adalah merupakan indikator praktek tingkat dua.

Hasil penelitian ini menunjukkan bahwa seluruh responden atau sebanyak 57 orang $(100 \%)$ responden memiliki sikap dengan kategori sedang. Hasil penelitian Kurniawati (136137) memperlihatkan bahwa ibu nifas mengaku jika bidan di desa tidak memberikan kapsul tersebut, ibu nifas seharusnya meminta kepada bidan yang membantu persalinan. Sikap positif ini dilakukan karena informan ibu nifas tersebut telah mengetahui pemberian kapsul vitamin A pada ibu nifas sangat bermanfaat untuk kesehatan ibu dan bayi. Hasil penelitian Kurniwati (136) menunjukkan bahwa ibu nifas memiliki sikap yang positif terhadap konsumsi kapsul 
vitamin A, hal ini dapat dilihat dari ibu nifas yang menerima kapsul vitamin A yang diberikan dan memberikan respon dengan bertanya terkait manfaat dan cara mengkonsumsi kapsul vitamin A. Hasil penelitian Susilowati (33-34) menunjukkan bahwa sikap dalam kategori baik akan cenderung membuat implementasi pemberian vitamin A dalam kategori baik sedangkan sikap dalam kategori kurang cenderung memiliki implementasi pemberian vitamin A dalam kategori kurang.

Sikap positif yang ditunjukan oleh ibu nifas dalam penelitian dapat dilihat dari ibu nifas yang bertanya atau meminta kapsul vitamin A jika tidak diserahkan oleh bidan desa. Ibu nifas juga menyatakan kapsul vitamin A yang diberikan sangat bermanfaat untuk kesehatan ibu dan bayi sehingga ibu nifas menyatakan membutuhkan kapsul vitamin A untuk kesehatan ibu dan bayi.

Sesuai dengan Keputusan Menteri Kesehatan RI Nomor 828/MENKES/SK/IX/2008 bahwa pelayanan nifas sesuai standar adalah pelayanan kepada ibu nifas sedikitnya 3 kali, pada 6 jam pasca persalinan sampai 3 hari; pada minggu ke II, dan pada minggu ke VI termasuk pemberian kapsul vitamin A sebanyak 2 kali. Hal ini sejalan menurut Kementrian Kesehatan (2010) bahwa perawatan kesehatan dasar anak dengan pemberian 2 buah kapsul vitamin A yang diminum selama masa nifas. Hal ini menunjukkan bahwa pemberian kapsul vitamin A termasuk didalam pelayanan nifas.

Sikap merupakan reaksi atau respon seseorang yang masih tertutup terhadap suatu stimulus atau objek. Sikap tidak langsung dilihat tetapi hanya dapat ditafsirkan terlebih dahulu dari perilaku yang tertutup. Sikap secara nyata menunjukkan konotasi adanya kesesuaian reaksi terhadap stimulus tertentu yang dalam kehidupan sehari-hari adalah merupakan reaksi yang bersifat emosional terhadap stimulus sosial. Secara umum sikap dapat dirumuskan sebagai kecenderungan untuk merespon (secara positif atau negatif) terhadap orang, objek atau situasi tertentu. Sikap mengandung suatu penelitian emosional/afektif (senang, benci, sedih, setuju). Selain bersifat positif dan negatif, sikap memiliki tingkat kedalaman yang berbeda-beda (sangat benci, agak benci, tidak setuju).

\section{Tindakan Ibu Nifas dalam mengkonsumsi Kapsul Vitamin A}

Menurut Kementerian Kesehatan RI (139), melalui Direktori Bina Gizi Masyarakat menyatakan bahwa seorang ibu nifas harus mendapatkan 2 buah kapsul vitamin A berwarna merah. Hal ini sejalan dengan pernyataan dari The International Vitamin A Consultative Group (IVACG) yang mengeluarkan rekomendasi bahwa seluruh ibu nifas seharusnya menerima 400.000 SI atau dua kapsul dosis tinggi @ 200,000 SI. Seorang ibu nifas harus mengkonsumsi kapsul vitamin A pada dua periode waktu yaitu pertama segera setelah melahirkan, kedua di berikan setelah 24 jam pemberian kapsul vitamin A pertama.

Hasil penelitian ini menunjukkan bahwa sebagian besar responden memiliki tindakan konsumsi kapsul vitamin A dalam kategori sedang yaitu sebanyak 52 orang (91,2\%) dan tindakan konsumsi kapsul vitamin A kategori buruk yaitu sebanyak 5 orang (8,8\%). Hasil penelitian Bando (4) memperlihatkan hanya sebesar 51,2\% ibu nifas mendapatkan kapsul vitamin A, hal ini disebabkan masih banyak ditemukan ibu nifas yang tidak mendapatkan kapsul vitamin A sebanyak 2 kapsul dari ibu bidan sehingga konsumsi kapsul vitamin A 
sebanyak 2 kapsul menjadi tidak banyak. Hasil penelitian Sandjaja (4-5) juga memperlihatkan masih ditemukannya ibu nifas yang tidak mengkonsumsi kapsul vitamin A yang disebabkan ibu nifas tidak mengetahui lokasi puskesmas terdekat, lokasi bidan praktik terdekat.

Hasil penelitian Kusumawati (33-35) memperlihatkan bahwa konsumsi vitamin A di Desa Sruwohrejo Kecamatan Butuh Kabupaten Purworejo tahun 2018 yaitu sebesar 34 responden dengan presentasi $(87.2 \%)$, hal ini tidak terlepas dari pengetahuan responden yang cukup baik . Hasil penelitian Susilowati (33-34) menunjukkan bahwa tindakan ibu nifas dalam mengkonsumsi kapsul vitamin A tidak terlepas dari faktor bidan dan tenaga kesehatan yang kurang mendukung secara nyata pemberian kapsul vitamin A. Kurniawati (138) mengungkapkan dalam penelitiannya bahwa ketersediaan kapsul vitamin A di klinik bidan atau di puskesmas menjadi salah satu faktor yang membuat ibu nifas tidak mengkonsumsi kapsul vitamin A secara tepat waktu. Hasil penelitian Putri (7-8) menunjukkan bahwa ibu nifas memiliki tingkat kepatuhan yang tinggi dalam mengkonsumsi kapsul vitamin $\mathrm{A}$, hal ini tidak terlepas dari ibu nifas yang telah mendapatkan informasi tentang vitamin A dengan baik.

Banyak faktor yang dapat mempengaruhi ibu nifas dalam mengkonsumsi kapsul vitamin A seperti pengetahuan ibu yang rendah, akses pelayanan kesehatan, tempat pelayanan kesehatan, tempat persalinan juga mempengaruhi cakupan pemberian kapsul vitamin A pada ibu nifas. Jarak rumah ibu nifas ke pelayanan kesehatan baik itu puskesmas dan klinik bidan menjadi salah satu faktor yang membuat ibu nifas mengkonsumsi kapsul vitamin A tidak sesuai waktu yang ditentukan.

Hasil penelitian menunjukkan responden mayoritas memiliki tindakan yang sedang dan hanya sebahagian kecil memiliki kategori tindakan baik, hal ini dikarenakan responden belum sepenuhnya melakukan tindakan konsumsi kapsul vitamin A secara baik dan benar. Masih banyak terdapatnya ibu nifas yang hanya mengkonsumsi satu buah kapsul vitamin A dan waktu mengkonsumsi vitamin A yang terlalu lama dari yang dianjurkan pemerintah padahal pemerintah sudah menetapkan bahwa setiap ibu nifas harus mengkonsumsi kapsul vitamin A sebanyak 2 buah kapsul dengan ketentuan satu kapsul segera setelah melahirkan dan kapsul kedua dikonsumsi setelah 24 jam pertama. Tindakan yang diambil responden juga tidak terlepas dari pengetahuan yang dimiliki responden, tindakan dalam mengkonsumsi kapsul vitamin A yang tidak tepat waktu juga tidak terlepas dari responden yang tidak mengetahui ketentuan waktu mengkonsumsi kapsul vitamin A dan manfaat yang akan diterima jika mengkonsumsi kapsul vitamin A sesuai waktu yang ditentukan.

\section{KESIMPULAN}

Ibu nifas yang menjadi responden di Kecamatan Kota Pinang Kabupaten Labuhanbatu Selatan mayoritas memiliki pengetahuan dalam kategori sedang dalam mengkonsumsi kapsul Vitamin A. Seluruh ibu nifas di Kecamatan Kota Pinang Kabupaten Labuhanbatu Selatan memiliki sikap mendukung konsumsi ibu nifas konsumsi Vitamin A. Ibu nifas di Kecamatan Kota Pinang Kabupaten Labuhanbatu Selatan mayoritas memiliki tindakan dalam mengkonsumsi kapsul Vitamin A.

Diharapkan agar petugas kesehatan Puskesmas di Kecamatan Kota Pinang dan pemuka masyarakat turut berpartisipasi dalam memberikan informasi mengenai konsumsi kapsul 
Vitamin A kepada ibu nifas. Diharapkan kepada ibu nifas untuk mengkonsumsi kapsul Vitamin A segera setelah diberikan oleh petugas kesehatan (bidan) setelah melakukan kunjungan nifas.

\section{DAFTAR PUSTAKA}

Bando, H. (2018). Analisis Suplementasi Vitamin A pada Ibu Nifas, Kelengkapan Imunisasi Dasar, dan PHBS Terhadap Morbiditas Bayi. Jurnal KESMAS, 7 (6).

Febriani , H. (2018). Hubungan Tingkat Pengetahuan Ibu tentang Vitamin A dengan Perilaku Pemberian Vitamin A pada Anak Usia 6-59 Bulan di Wilayah Kerja Puskesmas Miran Provinsi Maluku. Jurnal Kesehatan Masyarakat, 11 (1), 1-17

Gogia S, S. HS. (2010). Maternal Postpartum Vitamin A Supplementation of Mortality and Morbidity in Infancy a Systematic Review of Randomized Controlled Trials. International Journal of Epidemiology. 39, 1217-26.

Kementerian Kesehatan Republik Indonesia. (2010). Panduan Pelayanan Kesehatan Bayi Baru Lahir Berbasis Perlindungan Anak. Direktorat Kesehatan Anak Khusus.

Kementerian Kesehatan Republik Indonesia. (2010). Profil Kesehatan Indonesia 2009. Pusat Data dan Surveilens Epidemiologi. Jakarta

Kementerian Kesehatan Republik Indonesia. (2010). Riset Kesehatan Dasar 2010. Jakarta.Badan Penelitian dan Pengenbangan Kementrian Kesehatan RI.

Kementerian Kesehatan Republik Indonesia. (2016). Buku Kesehatan Ibu dan Anak. Jakarta. Kementerian Kesehatan RI.

Kementerian Kesehatan Republik Indonesia. (2018). Riset Kesehatan Dasar 2010. Jakarta. Badan Penelitian dan Pengembangan Kementerian Kesehatan RI.

Kurniawati, R. S.(2015). Gambaran Pelaksanaan Pemberian Kapsul Vitamin A pada Ibu Nifas (Studi di Wilayah Kerja Puskesmas Kalibawang Kabupaten Wonosobo) . Unnes Journal of Public Health (UJPH )4 (2): 132-142

Kusumawati, P. D. (2018). Hubungan Tingkat Pengetahuan Ibu tentang Vitamin A dengan Ketepatan dalam Pemberian Vitamin A Pada Balita di Wilayah Kerja Puskesmas Sruwohrejo Kecamatan Butuh Kabupaten Purworejo. Jurnal Komunikasi Kesehatan, IX(2), 29-37

Oliveira MJM, B. DP, Middleton P, E CE. (2010).Vitamin A Supplementation Forpost Partum Women (Review). The Cochrane Colaboration. Wiley. 10:1-82

Prastiwi RS. (2010). Program Pemberian Vitamin A pada Ibu Nifas di Bidan Delima Ranting Timur Cabang Bantul Tahun 2010: [Diakses tanggal 21 April 2018]. Tersedia dari: URL:http:/ / digilib.unisayogya.ac.id/id/eprint/3586.

Putri, E. D. (2014). Hubungan Tingkat Pengetahuan Ibu Dengan Upaya Kepatuahan Pemberian Vitamin A pada Balita Di Puskesmas Wirobrajan Yogyakarta Tahun 2014. Karya Tulis Ilmiah. Sekolah Tinggi Ilmu Kesehatan 'Aisyiyah Yogyakarta.

Salam, A. (2018). Efek Suplementasi Vitamin A, Minyak Fortifikasi dan Edukasi Gizi Ibu Nifas terhadap Morbiditas Ibu dan Bayi. Jurnal MKMI, Vol. 14 No. 3, September 2018; 209-216.

Sandjaja, R. E. (2012).Cakupan Suplemtasi kapsul vitamin A pada Ibu Masa Nifas dan FaktorFaktor yang Memengaruhi di Indonesia Analisis Data Riskesdas 2010. Buletin Penelitian Sistem Kesehatan. 15(1),1-1

Susilowati, A. (2015). Faktor-Faktor yang berhubungan dengan Program Pemberian Kapsul Vitamin A pada Ibu Nifas oleh Bidan Desa di Wilayah Dinas Kesehatan Kabupaten Sleman. Jurnal Kesehatan Masyarakat, 3 (2), 30-40 
Wahyuni, E. (2018). Hubungan Asupan Seng dan Vitamin A dengan Kejadian Diare pada Anak Umur 1-5 Tahun. Holistik Jurnal Kesehatan, 12(3), 136-145

Yanti, T. B. (2015). Hubungan Pemberian Vitamin A dan Umur Saat Pemberian Imunisasi Campak dengan Kejadian Campak pada Bayi dan Balita di Kabupaten Bantul Tahun 2013-2014. Skripsi. STIKES Aisyiyah Yogyakarta. 